\title{
Erasing fear memories - key receptor and essential timeframe discovered
}

\author{
Shigenori KAWAHARA
}

Acta Pharmacologica Sinica (2011) 32: 1-2; doi: 10.1038/aps.2010.215; published online 20 Dec 2010

$\mathrm{I}^{\mathrm{t}}$ is clinically important to suppress or inhibit traumatic memories, which are formed after fearful experiences. In animal models, fear memory is formed by repetitive presentation of a tone paired with an electrical foot-shock ${ }^{[1]}$. It is well known that an extinction proto$\mathrm{col}$, in which the tone is repeatedly presented without the foot-shock, gradually decreases the pre-acquired fear response to the tone. However, this fear extinction protocol is not sufficient to erase the fear memory; fear responses may recover spontaneously or relapse under some conditions. If the fear memory is retrieved or reactivated by a single presentation of the tone without the shock $1 \mathrm{~h}$ before the extinction session, the fear responses are permanently removed by this retrieval-extinction protocol ${ }^{[2]}$. This suggests that a critical brain state is caused by the retrieval procedure, in which the fear memory becomes labile and can be destroyed by the subsequent extinction procedure. Clem and Huganir $^{[3]}$ have found a critical receptor for the permanent erasure of fear memories by this retrieval-extinction protocol. They focused on the $\mathrm{Ca}^{2+}$-permeable type of a-amino-3-hydroxyl-5-methyl4-isoxazole-propionate receptor $\left(\mathrm{Ca}^{2+}\right.$ permeable-AMPAR) located in the lat-

Graduate School of Science and Engineering, University of Toyama, 3190 Gofuku, Toyama 930-8555, Japan

Correspondence: Prof Shigenori KAWAHARA

(kawahara@eng.u-toyama.ac.jp) eral amygdala, an essential region of the brain for learning. They suggested that removal of $\mathrm{Ca}^{2+}$-permeable-AMPARs, the content of which in the synapses is elevated for a few days after fear conditioning, is responsible for the permanent erasure of the fear memory by that protocol.

First, they demonstrated an enhancement of $\mathrm{Ca}^{2+}$-permeable-AMPAR mediated excitatory postsynaptic currents in fear-conditioned animals, suggesting an incorporation of $\mathrm{Ca}^{2+}$-permeableAMPARs or a change of subunit composition of AMPAR to the $\mathrm{Ca}^{2+}$-permeable type. This increase of $\mathrm{Ca}^{2+}$-permeableAMPARs peaked at $24 \mathrm{~h}$ after conditioning and disappeared by d 7, whereas the total amount of AMPARs remained increased even after $7 \mathrm{~d}$. These results suggest the presence of an important time window, during which AMPARs transiently change their subunit composition to the $\mathrm{Ca}^{2+}$-permeable type. Increased $\mathrm{Ca}^{2+}$-permeable-AMPARs at $24 \mathrm{~h}$ after fear conditioning was also supported by an enhancement of longterm depression (LTD), which is caused by selective removal of $\mathrm{Ca}^{2+}$-permeableAMPARs that become abundant at that time.

Next, they examined the effects of memory retrieval on $\mathrm{Ca}^{2+}$-permeableAMPARs measured after extinction. They found that reactivation of the fear memory before the extinction session significantly decreased AMPA-mediated current, indicating that memory reactivation followed by extinction attenuates the potentiated transmission caused by fear conditioning. Electrophysiological and pharmacological examinations suggested that this reversal change of synaptic transmission is due to the selective removal of $\mathrm{Ca}^{2+}$-permeableAMPARs, which are enriched $24 \mathrm{~h}$ after conditioning. Consistent with this, LTD induction was greatly reduced in the animals receiving the retrievalextinction protocol, compared with those receiving extinction alone. This is because memory retrieval prior to the extinction removes the $\mathrm{Ca}^{2+}$-permeableAMPARs from the synapses, and so further reduction in synaptic transmission would not be observed. In addition, memory reactivation is not effective when carried out $7 \mathrm{~d}$ after the conditioning, when the $\mathrm{Ca}^{2+}$-permeable-AMPARs return to the basal level, supporting the idea that successful erasure of the fear memory requires an abundance of $\mathrm{Ca}^{2+}$ permeable-AMPARs at the time of the retrieval-extinction treatment.

Finally, they investigated the molecular mechanisms underlying the elevation of $\mathrm{Ca}^{2+}$-permeable-AMPAR content after fear conditioning, which is a prerequisite for removal of $\mathrm{Ca}^{2+}$-permeable-AMPARs by the retrieval-extinction protocol. It was reported that phosphorylation of the serine 845 (S845) residue of glutamate receptor 1 (GluR1) by protein kinase A (PKA) is required for stable expression 
of $\mathrm{Ca}^{2+}$-permeable-AMPARs ${ }^{[4]}$. Using mutant mice with an alanine substitution mutation of S845 (S845A), they showed that phosphorylation of $\mathrm{Ca}^{2+}$ permeable-AMPARs by PKA is critical for the increase of $\mathrm{Ca}^{2+}$-permeableAMPAR current and the enhancement of LTD $24 \mathrm{~h}$ after fear conditioning. These results suggest the importance of phosphorylation of S845 for the synaptic incorporation of $\mathrm{Ca}^{2+}$-permeableAMPARs. In parallel with the deficits in the post-conditioning dynamics of $\mathrm{Ca}^{2+}$-permeable-AMPARs, memory erasure by the retrieval-extinction protocol was impaired in these mutant mice. Because phosphorylation of $\mathrm{Ca}^{2+}$ permeable-AMPARs by PKA is blocked throughout the brain in these mutant mice, there is a possibility that the lack of the erasure effect might be due to impairments in other regions outside the lateral amygdala. Combined with other data, however, it is suggested that the transient up-and-down change in the amount of $\mathrm{Ca}^{2+}$-permeable-AMPARs in the lateral amygdala synapses has a crucial role in permanent erasure of the fear memory and that phosphorylation of $\mathrm{Ca}^{2+}$-permeable-AMPARs by PKA is involved in their up-regulation. Interestingly, S845A mutant mice showed a significant post-conditioning synaptic potentiation in the lateral amygdala and learned as successfully as the wildtype mice. These results indicate that phosphorylation of S845 and its resulting $\mathrm{Ca}^{2+}$-permeable-AMPAR dynamics are specifically related to the memory erasure processes triggered by the retrievalextinction protocol.

In addition to molecular strategies for treatment of traumatic memories, these data also provide important information on the right timing of the treatment: there is a critical or effective period for the memory erasure. Because $\mathrm{Ca}^{2+}$. permeable-AMPARs reach a maximum level $24 \mathrm{~h}$ after fear conditioning and then gradually decline within a few days, the treatment will only be effective within this time window. Further attempts to artificially induce $\mathrm{Ca}^{2+}$ permeable-AMPAR accumulation might remove the time limit and make the treatment successful beyond this narrow timeframe.

1 Herry C, Ferraguti F, Singewald N, Letzkus JJ, Ehrlich I, Lüthi A. Neuronal circuits of fear extinction. Eur J Neurosci 2010; 31: 599-612.

2 Monfils MH, Cowansage KK, Klann E, LeDoux JE. Extinction-reconsolidation boundaries: key to persistent attenuation of fear memories. Science 2009; 324: 951-5.

3 Clem RL, Huganir RL. Calcium-permeable AMPA receptor dynamics mediate fear memory erasure. Science 2010; 330: 1108-12.

4 He K, Song L, Cummings LW, Goldman J, Huganir RL, Lee H-K. Stabilization of $\mathrm{Ca}^{2+}$-permeable AMPA receptors at perisynaptic sites by GluR1-S845 phosphorylation. Proc Natl Acad Sci USA 2009; 106: 20033-8. 